\title{
К ВОПРОСУ ИЗМЕРЕНИЯ ЛОКАЛЬНЫХ ДЕФОРМАЦИЙ ВНУТРИ ОБРАЗЦА МЕТОДОМ ФОТОВЫЖИГАНИЯ СПЕКТРАЛЬНЫХ ПРОВАЛОВ
}

\author{
K. $K$. REBANE. LOKAALSETE DEFORMATSIOONIDE MOOTMISEST KATSEOBJEKTI SISEMUSES \\ SPEKTRITE FOTOSALKAMISE MEETODIL \\ K. $K$. REBANE. ON DETECTION OF THE DEFORMATIONS IN THE BULK OF SAMPLE'S \\ MATERIAL VIA PHOTOBURNING OF SPECTRAL HOLES
}

В [ $\left.{ }^{1}\right]$ предложено использовать фотовыжигание спектральных провалов (см. монографии $\left[{ }^{2}\right]$ и обзоры $\left.\left[{ }^{3}\right]\right)$ для определения поля деформаций (напряжений) в твердотельном образце. Среди новых перспектив особенно привлекательна возможность выжигать провалы в спектре нагруженного образца и исследовать связанные с напряжением изменения их положения и формы после снятия нагрузки. В $\left[{ }^{4}\right]$ описаны первые эксперименты (см. также [5]).

Цель настоящей заметки - обратить внимание на уникальные возможности метода для измерения деформаций в данной точке внутри образца.

1. В достаточно прозрачный для лазерного луча образец вводятся поглощающие этот луч фотопревращаемые примесные молекулы только в ту точку (точки или области), деформации около которой подлежат измерению (а также в реперную область сравнения, если потребуется). Под напряжением выжигается провал или провалы. После снятия напряжения они исследуются путем измерения спектра примесного поглощения, спектра возбуждения люминесценции или каким-либо другим методом измерения провалов в спектрах $\left[{ }^{2,3}\right]$. Измерение можно проводить как вдоль направления выжигающего луча, так и в любом другом направлении. В принципе можно также выжигать и измерять провал в напряженном состоянии образца одним и тем же лучом, что имеет, по-видимому, смысл делать при исследовании динамики разрушения образца.

2. В качестве датчиков в образец (который может теперь быть непрозрачным) можно ввести оптические волокна, нужные участки которых активированы примесями под фотовыжигание. Бесспорно, что дополнительное волокно изменяет поле напряжений, но это можно учесть. Можно комбинировать волокно с каплями вещества фотовыжигания.

Измерение на волокнах особенно целесообразно для исследования композиционных материалов, в частности, предназначенных для работы при сверхнизких температурах (космос, сложные установки жидкого гелия). Можно создать и трехмерную сетку из однородно или выборочно окрашенных волокон и решить задачу с помощью вычислений как квазитомографическую, но не видно, для каких именно задач это может оказаться целесообразным.

Автор признателен Я. Қикасу за обсуждение. 
1. Ребане К. К. // Изв. АН ЭССР. Физ. Матем., 1985, 34, № 4, 441-443.

2. Persistent Spectral Hole-Burning: Science and Applications (ed. W. E. Moerner). Berlin; Heidelberg; New York; London; Paris; Tokyo, Springer Verlag, 1988; Zero-Phonon Lines and Spectral Hole Burning in Spectroscopy and Photochemistry (eds. Olev Sild, Kristjan Haller). Berlin; Heidelberg; New York; London; Paris; Tokyo, Snringer Verlag, 1988.

3. Rebane, L. A., Gorokhovskii, A. A., Kikas, J. V. // Appl. Phys., 1982, B29, 235-250; Rebane, K. K., Gorokhouskii, A. A. // J. Lumin., 1987, 36, 237.

4. Ребане К. К., Гороховский А. А., Кикас Я. В., Малкин Е. И., Пальм В. В. // Письма в ЖЭТФ, 1988, 14, вып. 10, 935-939.

5. А. с. Способ регистрации распределения внутренних напряжений. К. К. Ребане, А. А. Гороховский, Я. В. Кикас, Е. И. Малкин, В. В. Пальм. - Заявка № 4191770/24-10. Положительное решение от 30. 08. 88.

Академия наук Эстонской ССР

Поступила в редакцию

$14 /$ XI 1988 